\title{
STUDY ON THE CHARACTERISTICS OF TILLER BLADE SHAPES BY SPRAY- WELDING HARDENING
}

Jain-Song Ju

Assistant Professor, Department of Biomechatronic Engineering, National Chiayi University, Chiayi, Taiwan 60004, R.O.C., jainsong@mail.ncyu.edu.tw

Follow this and additional works at: https://jmstt.ntou.edu.tw/journal

Part of the Mechanical Engineering Commons

\section{Recommended Citation}

Ju, Jain-Song (2007) "STUDY ON THE CHARACTERISTICS OF TILLER BLADE SHAPES BY SPRAY-WELDING HARDENING," Journal of Marine Science and Technology. Vol. 15: Iss. 3, Article 7.

DOI: $10.51400 / 2709-6998.2395$

Available at: https://jmstt.ntou.edu.tw/journal/vol15/iss3/7

This Research Article is brought to you for free and open access by Journal of Marine Science and Technology. It has been accepted for inclusion in Journal of Marine Science and Technology by an authorized editor of Journal of Marine Science and Technology. 


\title{
STUDY ON THE CHARACTERISTICS OF TILLER BLADE SHAPES BY SPRAY-WELDING HARDENING
}

\author{
Jain-Song Ju*
}

Key words: tiller blade, cultivation blade, nickel-base alloy, spray-welding mechanism, SUP-HT.

\section{ABSTRACT}

This study attempts to validate and analyze the mathematical models of the plowing dynamics and trajectory curve for tiller and cultivation blades of a rotary cultivator. Both blades are extensively used in Taiwan. The blade must be protected from intertwisting to ensure high efficiency and uniform resistance of the plow to soil. Theoretical and calculated cutting angles are found to be $85.88^{\circ}$ and $84.28^{\circ}$, respectively, while the theoretical and calculated edge-curve angles are $59.70^{\circ}$ and $58.31^{\circ}$. The present data confirmed that the tiller blades developed by local companies are suitable for the plowing environment in Taiwan. In order to reduce the cost from frequent change of the blade due to wear and tear, the Nickel-Base alloy powder welding technique was applied to increase the surface hardening of tiller blades. The surface temperature of coated blades measured by the infrared thermal imager has show that, at the measurement spots, both the instant heat image displayed in the thermal imager and the surface temperature of the heat radiation collected after eight seconds were consistent with earlier results. When thess six pieces of tiller blades were tested at the same time, the six sets of heat radiant temperatures of the corresponding points obtained from the thermal imager were found similar and evenly distributed. In the Schwingung Reibung Verschleiss (SRV) testing mechanism experiment, the duration of attrition for the coating and the abrasive parameters has shown that SUP-HT specimens performed better than the SUP-H specimens. The SUP-HT also has a better anti-oxidized function with a hardness parameter (HRc) of $58 \sim 60$. The adherence after compression has graded as Aclass under Scanning Electronic Microscopy (SEM). It can be proved that the coating surface of the tiller blades treated with alloy powder welding would increase uniformity, precision and stability when using the alloy powder spray-welding mechanism developed in this study. As it is applied to the real situation, the natural soil can free from the contamination of iron particle coming off the blades up to $618,000 \mathrm{~kg}$. Meanwhile, a labor cost of $7.5 \mathrm{hr}$ and equipment cost 4,620 NT can be saved per set of tractor, minimizing the cost of production.

Paper Submitted 03/17/06, Accepted 11/15/06. Author for Correspondence: J.S.Ju. E-mail: jainsong@mail.ncyu.edu.tw.

*Assistant Professor, Department of Biomechatronic Engineering, National Chiayi University, Chiayi, Taiwan 60004, R.O.C.

\section{INTRODUCTION}

Taiwan has around 833,176 hectares of farming land, occupying $23.14 \%$ of the entire island. Tractors with rotary tiller blades perform most of the tilling in the fields since the rotary tiller blades are extremely smooth and efficient in crushing the soil. More ferruginous particles are produced by wear as more tiller blades are utilized. Taiwan agricultural statistics indicate that Taiwan has 14,738 tractors and 13,870 sets of rotary blades, while 1,400 tractors and 1,450 sets of rotary blades are imported annually into Taiwan [1], estimated to represent around $71.5 \%$ of all agricultural machinery in Taiwan [21].

However, local farmers are used to purchase second hand tractors to reduce the coast. In order to fit the cultivation environment and the local users' habits, the power and efficiency of tractors and rotary need to be improved to increase their work utility.

According to marketing survey done by $\mathrm{Ju}$ et al. [12], currently there are four weak points in the second hand tractor market: (1) damage in the oil pump system, (2) waste gas produced by the engines, (3) the uncomfortness of the seat set, and (4) abrasiveness of the tiller blades. Among these, the attrition of tiller blades costs more for the users, and annually, 2.5 million set of tiller blades are replaced. Tractors working in the soil generate functional forces which plowing due to the compression to the soil, the soil resistance caused by plowing, the adhesive forces of the soil, and abrasive forces with the soil. The rate of attrition of tiller blades is depended on the frequency of the tractors operated. For example, a $100 \mathrm{hp}$ tractor that was attached to a set of $2.4 \mathrm{~m}$ large rotary tiller needs 74 pieces of tiller blades. For a 15 ha sandy loam soil, the blades should be replaced every $50 \mathrm{hrs}$, leaving the iron dust of the worn-out tiller blade into the soil, which is detrimental to the environment in the long run. In addition, the replacement of blades not only affects the efficiency of the job, but also increases the cost of operation. At present, the supply of tractors and large rotary tiller 
blades relief on the imports from abroad. Due to the yearly increase in the cost of purchasing tiller blades, the charge for tilling per 0.1 ha soil has increased by $20 \%$. As a result, the benefit of investment in farming is being dropped significantly. Therefore, in order to increase the farmer's return, it is necessary to solve this problem.

The attrition rate of the tiller blade depends on the tractor workload. Yamada et al. [23] found that four major factors determine the attrition from the tiller blades: (1) soil conditions, (2) quality of the tiller blades, (3) their mechanical conditions, and (4) operating conditions. The farming conditions are linked to the soil mechanics. A survey of the soil on farms, performed by the Kogi Agriculture and Forestry Technology Institute (Japan) revealed that a higher percentage of sand and silt increases the speed of attrition from the tiller blades. The blade attrition depends on the quality of the material, their solidity, the spray emulsion, the heat treatment, their depth, toughness and shape, the cutting angle, the blade edges, the curvature and the scoop angle. The blade attrition is correlated with mechanical output forces, the tiller blade arrangement, the repeated crushing of the soil and other factors. The operating conditions also depend on the tilling area, the soil compression, the impact loads, the resistance due to abrasion and the sharpening.

A well-designed blade plows the soil smoothly without any friction between the backside of the blade and the soil. The blade relief angle is given by $\gamma$, and ideally $\beta_{1}<\beta$ [17]. If $\gamma<10^{\circ}$, then the plowing and throwing are performed very poorly. A larger relief angle $\gamma$ means more powerful plowing and throwing. The general preferred angle for plowing is $20-30^{\circ}$ [16]. To maximize the effectiveness of plowing and to unify the resisting force, the optimum cutting angles of the blade are between $80^{\circ}$ and $88^{\circ}$, and the plowing angles are between $50^{\circ}$ and $60^{\circ}$, since the blade can avoid intertwining with the grass. These results correlate with those of previous studies $[11,15,19]$.

The technique of surface hardening on the metal has been used for a long period. All alloys share the features of tolerance to attrition, corrosion, impact, and high temperature. The application of such a technology is widely used in various industries, such as aviation, petroleum, architecture, transportation, nuclear power, lumber processing, plastics, glass, automobile, and agricultural mechanics. This technology has significantly benefitted our industry [2, 13, 14, 22, 24].

Zheng et al. [25] have applied the ceramics spraying technology on tiller blades to test its tolerance to the attrition in soil tanks and field trials. In their studies, seven sets of blades were used, and the walking distance during operation was taken as a variable. The level of attrition was determined by comparing the quality and quantity of attrition on the blade surfaces. The results showed that the attrition on both sides at the top of the blade was significantly severe. The attrition of the surface increased in proportion to the degree of penetration into the soil. Although the tiller blade with ceramic spray had significantly its tolerance to attrition, the ceramic spray came off its surface easily.

$\mathrm{Ju}$ et al. [4] has proposed the application of a Nickel-Base alloy powder spray-welding and hardening treatment to a tiller blade in order to harden the surface of the blade, and to explore the applicability of such welded blades in field operation. The results revealed that spray-welding blade that operated in the sandy soil was more efficient, and the tilling area per blade increased from 15 ha to 45 ha, which was able to save $7.5 \mathrm{hrs}$ of replacement time, and save 1,743 NT dollars on the equipment. Meanwhile, it not only reduced the cost, but also decreased the quantity of iron dust left in the soil. If the soil was filled with sand and gravel, the possibility of a welded blade being crushed was $1.5 \%$ higher than that of an untreated blade. The reason was attributed to improper heating, causing the lack of uniformity and stability of the welding surface. A better alloy powder, combined with automatic machinery research and development, can be expected to solve this long-term problem.

The objectives of this study are to apply the technique of alloy powder spray-welding on the tiller blades and use an automatic mechanism to harden the tiller blade surface to improve its material stability and increase tolerance to attrition. Therefore, the life of the blade is expected to extend and a good quality soil environment can be maintain.

\section{THEORY}

\section{Geometry of scoop-surface of tiller blades}

The geometry of tiller blades is considered to be the most important factor in their design, since both the shape of the blade tip and the length of the tiller blade facilitate cutting. The blade tip width exceeds the blade length. The contact between the blade and the soil moves slowly from the handle near the center of the shaft to the blade length. The blade tip cuts the intact grass at the boundary between the blade length and the blade tip. The grass can also be thrown away or torn off by the outward rotation. This class of blade performs well in the soil in Asia, and is extensively adopted in Taiwan and Japan. Figure 1 illustrates both the blade tip and the blade length, as segments Dn and ED, respectively. The blade length must meet two conditions, namely the absence of intertwisting and a low drag force 


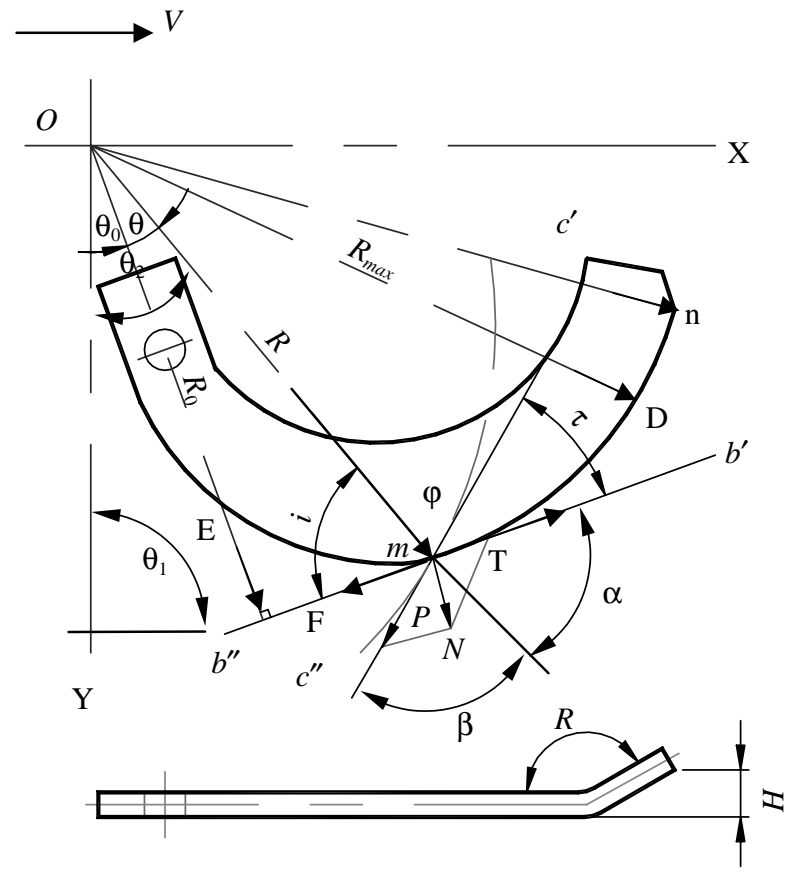

Fig. 1. The shapes' scoop-surface and cutting function of tiller blades.

during cultivation.

The cutting conditions are $T \geq F$ (Figure 1 )

$$
\begin{aligned}
& T=N \cot \tau \\
& F=N \tan \varphi \\
& \cot \tau>\tan \varphi \\
& \tan \left(90^{\circ}-\tau\right)>\tan \varphi \\
& 90^{\circ}-\tau>\varphi \quad \therefore \tau<90^{\circ}-\varphi
\end{aligned}
$$

where

$$
\begin{aligned}
\varphi= & \text { denotes the friction angle of the rootstock with } \\
& \text { respect to the blade edge } \\
T= & \text { cutting force (in } \mathrm{N}) \\
F= & \text { friction force }(\text { in } \mathrm{N}) \\
N= & \text { normal force }(\text { in } \mathrm{N})
\end{aligned}
$$

The blade length is part of an Archimedean curve whose parametric equation is,

$$
R=R_{\circ}(1+K \theta)
$$

Conside $i$ as the angle between $b^{\prime} b^{\prime \prime}$ and line $O m$;

$$
\begin{aligned}
& \theta_{\circ}+\theta=\theta_{2} \\
& \theta_{1}=i+\theta_{2} \\
& \therefore i=\theta_{1}-\theta_{2} \\
& \tan i=\tan \left(\theta_{1}-\theta_{2}\right) \\
& \quad=\frac{\tan \theta_{1}-\tan \theta_{2}}{1+\tan \theta_{1} \tan \theta_{2}}
\end{aligned}
$$

However,

$$
\tan \theta_{i}=\frac{d x}{d y}
$$

Thus, when $\theta$ is considered to be parametric, $R=$ $R_{\circ}(1+K \theta)$ a polar coordinates equation for the curve of tiller's blade scoop surface can be change to an orthogonal coordinate equation.

$$
\begin{aligned}
& x=R(\theta) \sin \theta_{2} \\
& y=R(\theta) \cos \theta_{2}
\end{aligned}
$$

Eq. (3) gives

$$
\begin{aligned}
\tan \theta_{1} & =\frac{d x}{d y}=\frac{d x / d \theta}{d y / d \theta}=\frac{R^{\prime}(\theta) \sin \theta_{2}+R(\theta) \cos \theta_{2}}{R^{\prime}(\theta) \cos \theta_{2}-R(\theta) \sin \theta_{2}} \\
& =\frac{R^{\prime}(\theta) \tan \theta_{2}+R(\theta)}{R^{\prime}(\theta)-R(\theta) \tan \theta_{2}}
\end{aligned}
$$

Substituting Eq. (4) into (2) yields,

$$
\begin{gathered}
\tan i=\frac{\frac{R^{\prime}(\theta) \tan \theta_{2}+R(\theta)}{R^{\prime}(\theta)-R(\theta) \tan \theta_{2}}-\tan \theta_{2}}{1+\tan \theta_{2}\left[\frac{R^{\prime}(\theta) \tan \theta_{2}+R(\theta)}{R^{\prime}(\theta)-R(\theta) \tan \theta_{2}}\right]} \\
\tan i=\frac{R^{\prime}(\theta) \tan \theta_{2}+R(\theta)-R^{\prime}(\theta) \tan \theta_{2}+R(\theta) \tan ^{2} \theta_{2}}{R^{\prime}(\theta)-R(\theta) \tan \theta_{2}} \\
=\frac{R(\theta)\left(1+\tan ^{2} \theta_{2}\right)}{R^{\prime}(\theta)-R(\theta) \tan \theta_{2}+R^{\prime}(\theta) \tan \theta_{2}+R(\theta) \tan _{2}} \\
\therefore \tan i=\frac{R^{\prime}(\theta)-R(\theta) \tan \theta_{2}}{R^{\prime}(\theta)}=\frac{R_{\circ}(1+K \theta)}{R_{\circ} K}=\frac{1+K \theta}{K} \\
i=\tan ^{-1} \frac{1+K \theta}{K}
\end{gathered}
$$

Although the angle $i$ increases with the angle $\theta$, the angle $\tau$ decreases as determined by the graphical analysis. The low $\tau$ positively affects the cutting work.

Another close solution [17, 20] can be obtained using polar coordinates on the spiral line (Figure 2). The edge-curve angle $\alpha$ was obtained from the experiments performed in Taiwan. The edge-curve angle $\alpha_{t}$ at the tip portion of such a straight blade as shown of 

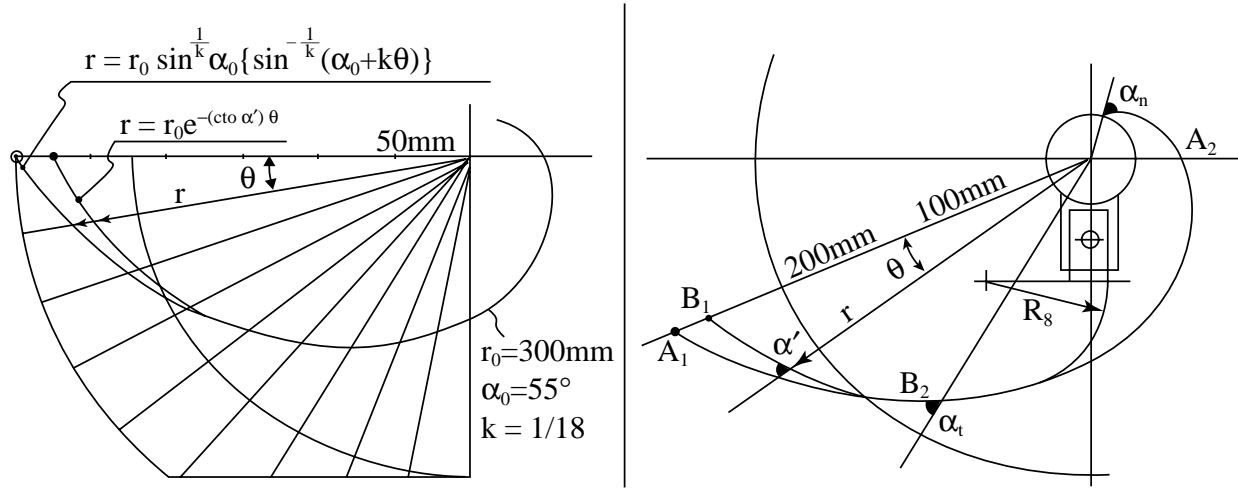

Fig. 2. Drawing process of planning design [17].

Figure 2 is recommended as $52.0^{\circ}$ [11]. The spiral trajectory and rotary radius of the blade, given by $R$, can be computed from the following parametric Eq. (6). These equations have the same result as Eq. (5).

$$
\alpha=\alpha_{t}+\left[\left\{\tan ^{-1} \frac{n \pi \sqrt{H(2 R-H)}}{30 V-n \pi(R-H)}\right\}+90^{\circ}\right]
$$

Where

$$
\begin{aligned}
& n=\text { rotary speed }(\text { in } \mathrm{rpm}) \\
& V=\text { Forward speed of tractor }(\mathrm{cm} / \mathrm{sec}) \\
& H=\text { depth of working (in } \mathrm{cm}) \\
& R=\text { rotation radius of the blade }(\text { in } \mathrm{cm})
\end{aligned}
$$

\section{Equations for the cultivation angle curves}

The trajectory curve of the blade, the rotary radius direction and the tangent curve of the trajectory converge at one point, generating a cutting angle of $\beta$ (Figure 3).

First, adopt Eq. (7) to compute angle $\beta[17,18]$. The base angle of the blade scoop $\beta_{1}$ can be easily computed with Eq. (8).

$$
\beta=\cos ^{-1}\left\{\frac{30 V}{R} \sqrt{\frac{H(2 R-H)}{(30 V)^{2}-60 n \pi V(R-H)+(R n \pi)^{2}}}\right\}
$$

$$
\beta_{1}=\beta-\gamma
$$

Eq. (9) is then utilized to compute the moving speed of the cultivation $v$ [17]. The acceleration value of the movement can be computed with Eq. (10), using the data of different tiller blades listed in table 1 .

$$
v=\frac{n \pi R\left(\left(n \pi c_{1}-30 V\right) \times \tan \left(180^{\circ}-\gamma-\tan ^{-1} \frac{-n \pi \sqrt{H(2 R-H)}}{30 V-n \pi c_{1}}\right)+n \pi \sqrt{H(2 R-H)}\right)}{30 \sqrt{\left(30 V-n \pi c_{1}\right)^{2}+n^{2} \pi^{2} H(2 R-H)} \times \tan \left(180^{\circ}-\gamma-\tan ^{-1} \frac{-n \pi \sqrt{H(2 R-H)}}{30 V-n \pi c_{1}}\right)}
$$

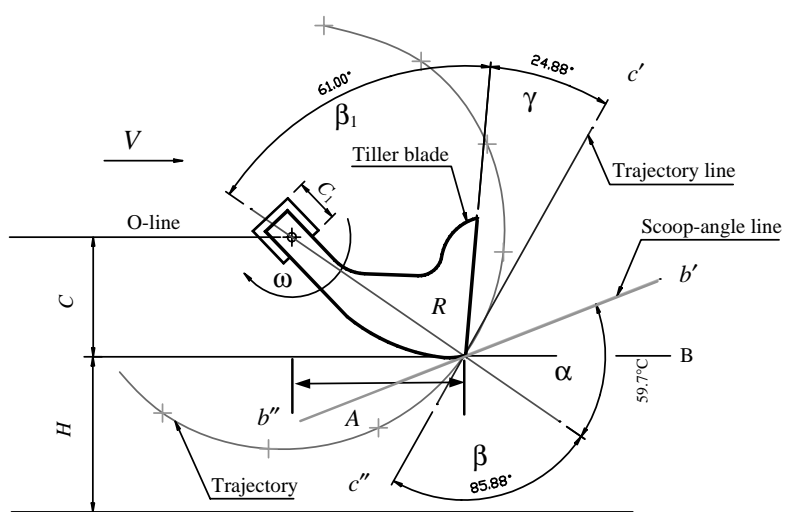

Fig. 3. The trajectory curves of the different angles of the tiller blades while plowing.

Table 1. Operational model for different types of tiller blades

\begin{tabular}{lcccc}
\hline Blade types & $v(\mathrm{~cm} / \mathrm{sec})$ & $n(\mathrm{rpm})$ & $\gamma$ & $a\left(\mathrm{~cm} / \mathrm{sec}^{2}\right)$ \\
\hline Cultivation blade & $20-30$ & $300-400$ & $5^{\circ}-10^{\circ}$ & $0-v$ \\
Cultivation broken bit blade & $30-40$ & $250-300$ & $10^{\circ}-15^{\circ}$ & $2-3 v$ \\
Cultivation wasteland blade & $40-60$ & $150-250$ & $15^{\circ}-20^{\circ}$ & $0-v$ \\
Tiller blade & $40-60$ & $150-300$ & $20^{\circ}-30^{\circ}$ & $2-3 v$ \\
Cutting blade & $20-30$ & $250-500$ & $20^{\circ}-30^{\circ}$ & $2-3 v$ \\
\hline
\end{tabular}




$$
a=\frac{v}{t} \quad \mathrm{~cm} / \mathrm{sec}^{2}
$$

Finally, Eq. (11) was utilized to compute time $t$ for cultivation [11]. Dividing the time into several equal parts can simplify the calculation. Parameters $r$ and $\theta$ can be derived from Eqs. (12) and (13).

$$
\begin{aligned}
& t=\frac{-(V+v)+\sqrt{(V+v)^{2}+2 a \sqrt{R^{2}-C^{2}}}}{a} \\
& r=\sqrt{C^{2}+A^{2}} \\
& \theta=\sin ^{-1}\left[\frac{C}{r}\right]-\frac{n \pi t}{30}
\end{aligned}
$$

where

$$
\begin{aligned}
& t=\text { tilling times (in sec) } \\
& \begin{aligned}
& c_{1}= \text { hard soil that cannot be mechanically tilled (in } \\
&\mathrm{cm})
\end{aligned} \\
& \begin{aligned}
r=\text { radius of the polar coordinates (in } \mathrm{cm}) \\
\theta=\text { rotating angles }\left(\mathrm{in}^{\circ}\right) \text { of the polar coordinates }
\end{aligned}
\end{aligned}
$$

\section{Analysis of motion performance Mechanism}

This study analyzes the displacement and velocity of a crank-slider linking for spray gun (Figure 4). Mechanism analysis using MATLAB program was able to evaluate the motion trajectories precisely, and found that the displacements of slider $r_{3}$ at the upper and lower strokes were unequal, which could not be obtained by drawing manually. The spray gun lever $r_{4}$ keeps horizontal when the crank rotates from its initial position, in which $P_{y}$ must be fixed above the middle of the moving path of point $D$. Then, the tilt-up and tilt down ranges of the spray gun lever $r_{4}$ were not symmetrical. The maximum linear velocities of slider $r_{3}$ occurs both at $\theta_{1}$ more than $180^{\circ}$ and less than $360^{\circ}$, while the time $A_{C}$ was zero. When $P_{y}$ was fixed in the middle of the moving path of the point $D$, the spray gun lever $r_{4}$ remained in the tilt-down position when the crank stayed at the initial position, and the tilt-up and tilt-down ranges of spray gun $r_{4}$ were symmetrical. Therefore, the factors that affect the tilt range of $r_{4}$ were the position of $P$ relative to $D$, or, the length of $r_{1}$ and $r_{2}$ [3].

Consider $\triangle A B C$,

Displacement: $r_{1} e^{i \theta_{1}}-r_{2} e^{i \theta_{2}}-r_{c} e^{i \theta_{c}}=0$, calculate $\theta_{2}$ and $r_{c}$

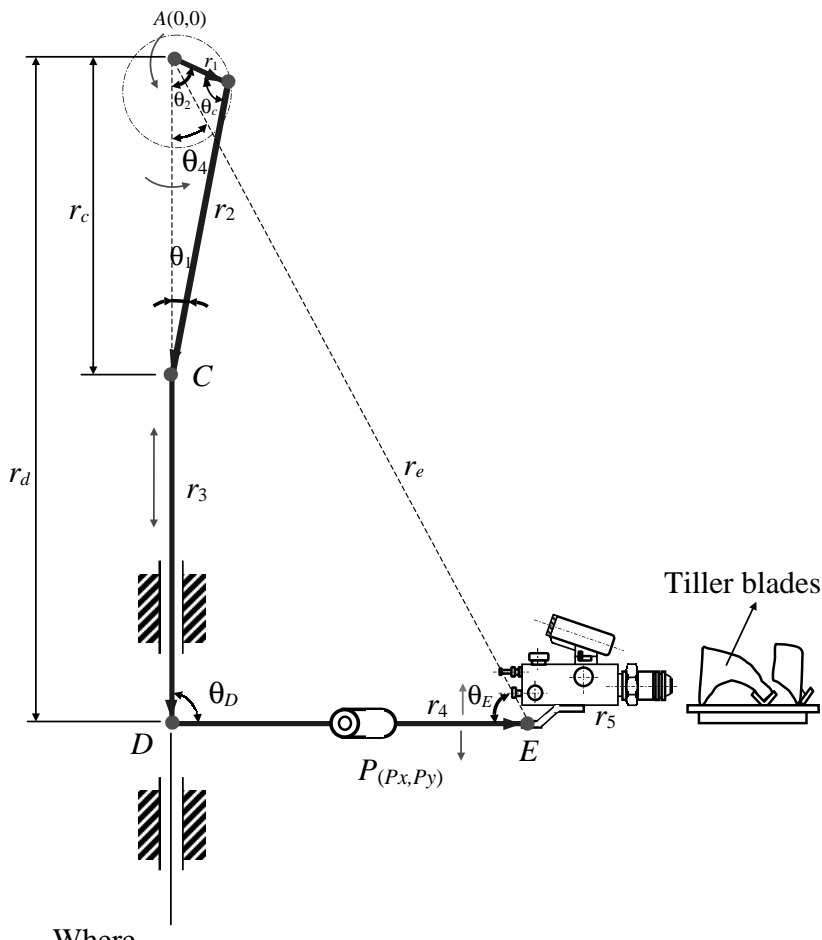

Where

$r_{1}, r_{2}, r_{3}, r_{4}$ is linkage, $r_{5}$ is spray gun

Fig. 4. Vector diagram of integrated eccentric and swing machinery.

Velocity: $r_{1} i \omega_{1} e^{i \theta_{1}}-r_{2} i \omega_{2} e^{i \theta_{2}}-\frac{d r_{c}}{d t} e^{i \theta_{c}}-v_{C} i \omega_{c} e^{i \theta_{c}}$ $=0$, calculate $\omega_{2}$ and $v_{C}$

Consider slider $r_{3}$ and linkage $r_{4}$,

Displacement: $r_{c} e^{i \theta_{c}}+r_{3} e^{i \theta_{3}}-r_{d} e^{i \theta_{D}}=0$, calculate $r_{d}$

Velocity: $v_{D}=v_{C}=P_{x} \times \omega_{4} \quad v_{E}=P E \times \omega_{4}$

Consider $\triangle A D E$,

Displacement: $r_{d} e^{i \theta_{D}}+r_{4} e^{i \theta_{4}}-r_{e} e^{i \theta_{E}}=0$, calculate $r_{e}$ and $\theta_{E}$

Velocity: $v_{D} e^{i \theta_{D}}+r_{4} i \omega_{4} e^{i \theta_{4}}-v_{E} e^{i \theta_{E}}-r_{e} i \omega_{E}^{i \theta_{E}}=0$, calculate $v_{E}$ and $\omega_{E}$

Analysis of the mechanism design combined with programming could obtain the design data quickly with a reasonable change in the linkage parameters.

\section{MATERIALS AND METHODS}

\section{Materials}

Colmonoy nickel-based alloys, Tiller blade, Cultivation blade. 


\section{Experimental equipment}

The configuration of the spray-welding mechanism was designed by Ju and $\mathrm{Du}[6,10]$ and is shown in Figure 5. It consisted of a spray gun, rocker linkage, lifting machine, sensor, Programmable Logic Controller (PLC), and an intermittence turntable. A converting motor was used to drive the rocker and the lifting combines. The amount of acetylene, oxygen, alloy powder, air from the compressor, and nozzle outlet were applied to control this motion. The whole system was able to perform an optimum operation (Table 2).

The swing angle of the spray gun was $60^{\circ}$ while the intermittent turntable was fixed. The weeding blades were set on a V-type seat in every $90^{\circ}$ for easy setup. A timer and the lifting mechanism simultaneously controlled by an air cylinder were used for driving.

The operations of the spray-welding mechanism are described as follows: The sensor for the lifting and rocker combination would induce the intermittent turntable mechanism to rotate one cycle after the spray gun completes its up-and-down motion seven times (down first). This would carry out the coating on one piece of weeding blade, which takes about 46 seconds when the velocities of the rocker and the lifter combination are kept at 58 and $75 \mathrm{~Hz}$, respectively. The next weeding blade would follow the previous one to finish the coat-

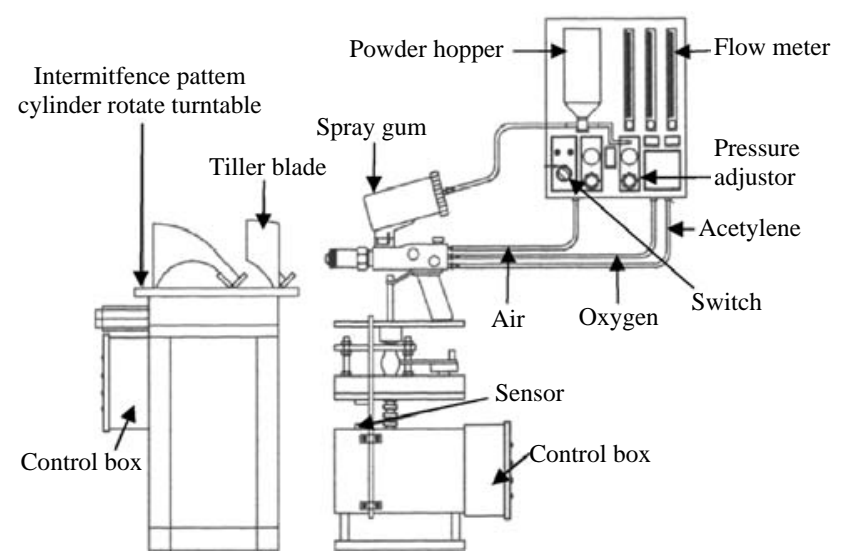

Fig. 5. Schematic diagram of the alloy powder spray-welding machine. ing job in the reverse order-that is, completing the upand-down motion seven times (up first).

In the agricultural cutting tools manufacturing method by Ju and Du [5], the weight percentages of the element composition (wt, \%) contained in the nickelbased alloy powder used on the experimental machine was C: $0.55 \sim 0.8, \mathrm{Cr}: 14 \sim 16, \mathrm{Si}: 3.9 \sim 4.9$, Fe: $2.4 \sim$ 4.6, B: $3.0 \sim 3.4$, Ni Balance (76.15 73.7). In terms of material characteristics, the hardness of the nickelbased alloy (C-scale) is $58 \sim 63$, the diameter of particle is $39 \sim 106 \mu \mathrm{m}$, the condensation is $8.08 \mathrm{~g} / \mathrm{cm}^{3}$, and the melting temperature is $1405^{\circ} \mathrm{C}$. The technology of applying spray-welding on the tiller blades presented an efficient result as the designed goal $[7,12]$.

\section{Hardware:}

1. Japan's NIPLO rotary plough (DCH2400), $2.4 \mathrm{~m}$ in width.

2. Tractor: MF-6255-R, Landini-115-R, SAME-110-R and ISEKI-10510-R, two of each.

3. The apparatus: the rotary torque shaft, the strain amplifier, the data recorder, the slide ring, the small interflow generator and the constant voltage regulator connected [11].

4. Infrared thermal imager: Sweden AGEMA Company (TVS-120 model).

5. Schwingung Reibung Verschleiss testing mechanism: Germany Optimal Company (KJ-5000 model).

6. Multi-Function Scanning Electron Microscope (MFSEM): Japan JEOL (JXA-840 model); Energy Dispersive Spectrometer (EDS): England LINKS Company (AN10000/85S model).

7. Hardness testing: MATSUZA WASEIKI hardness instrument.

\section{Software:}

1. MATLAB r12: for writing programs and drawing the polar plots.

2. AutoCAD 2000: for 3D plots and analyzing trajectory curves from the tiller blades used to plow the soil at various angles.

3. Visual Basic: for writing programs and to use the

Table 2. Main technique parameters of spray gun

\begin{tabular}{cccccccc}
\hline $\begin{array}{c}\text { Nozzle } \\
\text { No }\end{array}$ & $\begin{array}{c}\text { Range to } \\
\text { the object } \\
(\mathrm{mm})\end{array}$ & Oxygen & $\begin{array}{c}\text { Gas pressure } \\
\text { (MPa) } \\
\text { Acetylene }\end{array}$ & Air & $\begin{array}{c}\text { Air } \\
\text { compressor } \\
\left(\mathrm{m}^{3} / \mathrm{min}\right)\end{array}$ & $\begin{array}{c}\text { Powder } \\
\text { dispatch } \\
(\mathrm{kg} / \mathrm{h})\end{array}$ & $\begin{array}{c}\text { Spray-welding } \\
\text { thickness } \\
(\mathrm{mm})\end{array}$ \\
\hline 1 & 200 & 0.3 & 0.055 & 0.25 & 0.6 & 3 & 0.2 \\
1 & 200 & 0.4 & 0.065 & 0.35 & 0.6 & 4 & 0.25 \\
1 & 200 & 0.5 & 0.075 & 0.45 & 0.6 & 5 & 0.3 \\
\hline
\end{tabular}


infrared thermal imager to collect the instant heat image and its radiant temperature.

4. ANSYS: for analyzing the structural force of the tiller blade and the changes of the heat trasmission on its surface.

\section{METHODOLOGY}

This study attempts to validate and analyze the mathematical models of the plowing dynamics and trajectory curve for tiller and cultivation blades of a rotary cultivator. Both blades are extensively used in Taiwan. An alloy powder spray-welding mechanism is used to harden the surface of the blades. Infrared thermal imager is used to collect the surface temperature data. In order to test the efficacy of the spray-welding alloy, experiments are conducted in a laboratory setting to analyze the attrition life expectancy of sample-welded layers. In terms of field experiments, the spray-welded blades are installed on sample tractors to implement testing in sandy-loam and gravel soil. A detailed methodology is given in the following.

\section{Analysis of the tiller blades angle when plowing, turn- ing and throwing}

A tiller blade utilized widely in Taiwan was adopted as the target for analysis in this study (Figure 3); a threedimensional graph was drawn with an Auto CAD system to describe the trajectory curve of the edge of the blade, with the tilling pitch set to $60 \mathrm{~mm}$, and the edge moving $5 \mathrm{~mm}$ per $30^{\circ}$ of rotation. The angles of cutting $\beta$, the plough-edge curve $\alpha$, the blade scoop-angle $\beta_{1}$ and the relief angle $\gamma$ can be obtained from the graph. These data were inserted into Eqs. (6) and (7), and compared with the data in previous literature to determine whether these values satisfy the constraints or the maximization of the efficacy in Taiwan's soil.

\section{Design of blade curve and its application}

The blade types controls the design of the standard operation based on their characteristics. Blades sold in the Taiwan local market are tiller and cultivation blades, which differ significantly in their curves, and have distinct characteristics. To clearly define the plowing characteristics of these two blades, the acceleration is set at $a=3 v\left(\mathrm{~cm} / \mathrm{sec}^{2}\right)$ when a tiller blade has a relief angle of $\gamma=25^{\circ}$. For the cultivation blade, when $\gamma=10^{\circ}$, set $a=v\left(\mathrm{~cm} / \mathrm{sec}^{2}\right)$. The data obtained from the actual field testing and from the computations based on the formulae can be programmed into MATLAB r12 software, and curves of the two blades are drawn in the polar coordinates.

\section{Temperature measurement via Infrared thermal imager}

For temperature measurement, the alloy powder on the welded layer of the blades are heated up to the melting point (app. $1050^{\circ} \mathrm{C}$ ) and scattered equally on the surface, by using the Infrared Thermal Imager's automatic instant monitor screen and recording software, to measure the surface temperatures per second until the heat radiation occurred. According to the previous data [9], the heat imager per second of the surface heat radiation was approximately $50^{\circ} \mathrm{C}$. In this study, the process was repeated on six sets of tiller blades and stored the temperature data and images in the hard drive for further data analysis.

\section{Experiment on the attrition of nickel-based alloy welded layer}

In order to look for the alloy's best parametric data for its production from the embedded layers, spring steel (SUP-9) coated with spray-welding and nickel-based alloy welded layer was taken as the target material, and applied different testing conditions (e.g. weight, force, frequency, thickness, time, and sliding distance, etc.) to compare and analyze the attrition results.

\section{Field trial for attrition testing on the surface of tiller blades}

Two testing fields with different soil nature were selected in this experiment. One is located in Chiayi and Tainan Counties with gravel Sesbania soil and the other is located in Yuan County with seaside sandy-loam soil. The tractors for the experiment include MF-6255-R (Taiwan Great Land Co., Kaohsiung, Landini-115-R (Li Xin Co., Kaohsiung), SAME-110-R (Shang Shun Co., Chiayi) and ISEKI-10510-R (Jing Guan Co., Taipei). Four brand new tractors were conducted in this experiment. The tractors were respectively attached to a Japanese NIPLO rotary (DCH 2400) and equipped with 84 tiller blades with power between 100-110 HP. The operating speed was set at 1 vs. 4 gears at the first trial, and 2 vs. 4 gears for the second trial. On each 0.1 ha of the test land, they were operated twice. The tilling speed of P.T. O. and rotary was $1000 \mathrm{rpm}$ and the depth for tilling was $18 \mathrm{~cm}$. A tiller blade was replaced for every 5ha. The weight of each separate blade after operation and the time needed for replacement were determined and recorded for attrition comparison and evaluation. 


\section{RESULTS AND DISCUSSION}

Through implementing the research process and completing all design requirements, good results were obtained to confirm the applicability of alloy powder spray-welding technique on tiller blades.

\section{Analysis of the tiller blades while plowing, turning and throwing}

The blade did not intertwist only when the cutting angles and the plowing angles of the blade were $80^{\circ}-88^{\circ}$ and $50^{\circ}-60^{\circ}$, respectively. The cutting angle $\beta$ and the edge-curve $\alpha$, computed with Eqs. (6) and (7), were $85.88^{\circ}$ and $59.70^{\circ}$ respectively, which were consistent with the data reported in the literature. The angles for cutting change with the edge-curve, the velocity, the blade rotation speed and depth of working. The velocity of the tractor was a variable, given by $V$. Figures 3 and 6 plot the relationships among $R, \beta$ and $H$; $\beta$ increased with $R$ but decreased as $H$ increased. The relief angles $\gamma$ were functions of the increase in $H$ and the decrease in $R$. The relief angle $\gamma$ was opposite to the depth of working, while the plowing angle $\alpha$ was arbitrary. Hence, the plowing conditions and the position of the blade affected the relief angles $\gamma$ and the cutting angles $\beta$ during plowing.

The blade curves was classified into four shapes based on the blade scoop-angles $\beta_{1}$ of $90^{\circ}, 80^{\circ}, 60^{\circ}$ and $40^{\circ}$. These blade curves were tested in an outdoor soil trial with the system of Ju and Luan [8], with uniform soil. Table 3 shows the experimental results. The plowing torque was highest when the top of the blade was at a blade scoop-angle of $90^{\circ}$ or $40^{\circ}$. The peak and the maximum torsion were both minimal when the angle was $80^{\circ}$.

However, a relief angle of $5.10^{\circ}$ affected plowing, turning and throwing. The blade scoop-angles $\beta_{1}$ and the relief angle $\gamma$ of the tiller blades in Taiwan were $61.00^{\circ}$ and $24.88^{\circ}$. The present data are agreed with Japanese product which has a $\beta$ value of $84.16^{\circ}, \alpha$ value of $57.86^{\circ}, \gamma$ value of $26.30^{\circ}$ and Cultivation blade $\gamma$ value of $11.23^{\circ}$ and $\beta_{1}$ value of $72.93^{\circ}$, respectively. Analysis results of the curve of the angle at the top of the blade indicated that the proposed tiller blade design is consistent with the literature data. Hence, most of the blades in the tillers utilized in Taiwan are highly effective and in plowing, turning and throwing soil.

\section{Application of the designed plowing curves for tiller blades}

Tables 4 and 5 and Figure 6 compare the plowing data for the two blades with the calculated data in the polar coordinate system using the MATLAB r12 program using tiller blades with a relief angle of $\gamma=25^{\circ}$, $a=3 v\left(\mathrm{~cm} / \mathrm{sec}^{2}\right)$ and cultivation blades given by $\gamma=10^{\circ}$, $a=v\left(\mathrm{~cm} / \mathrm{sec}^{2}\right)$. The polar curve of the tiller blade indicates that a plowing and throwing angle of smaller than $25^{\circ}$ in the tiller blade results in highly effective plowing and throwing functions. A plowing and throwing angle of below $90^{\circ}$ for the cultivation blades minimizes the friction exerted on the blade as it enters the soil, minimizing cracking during plowing. The data presented herein correlate with those in the literature.

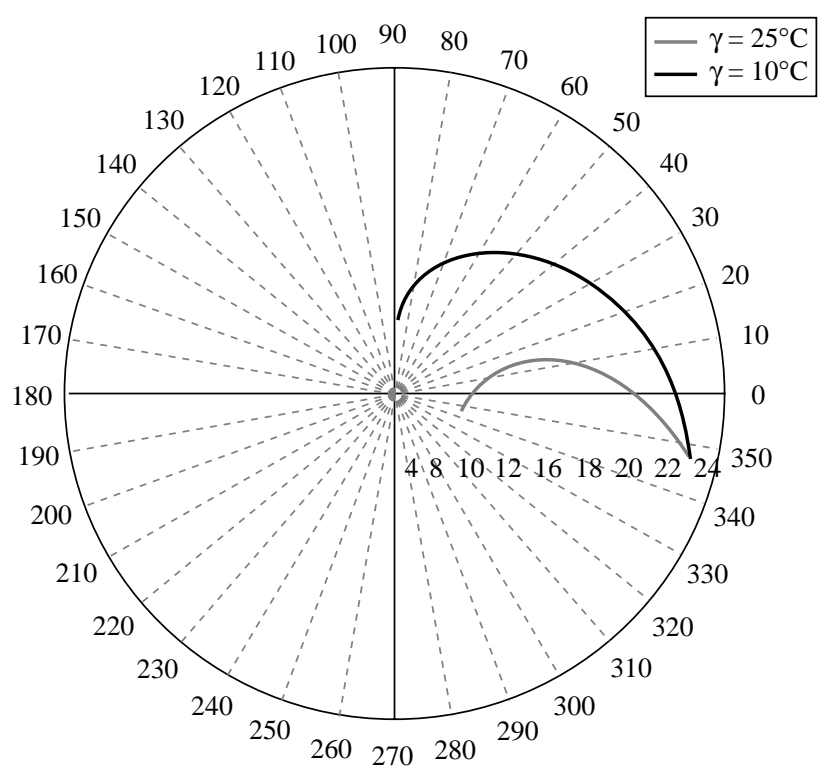

Fig. 6. The trajectory data in polar coordinate for tiller blades and cultivation blades, Tiller blade $\left(\gamma=25^{\circ}\right)$, Cultivation blade $\left(\gamma=\mathbf{1 0}^{\circ}\right)$.

Table 3. Comparison between tiller peak and maximum torque across different scoop-angles

\begin{tabular}{lcccc}
\hline Scoop-angle $\left(\beta_{1}\right)$ & $90^{\circ}$ & $80^{\circ}$ & $60^{\circ}$ & $40^{\circ}$ \\
\hline Peak $(\mu)$ kgf & $50-55$ & $42-46$ & $47-54$ & $50-58$ \\
maximum torque kgf & $45-50$ & $38-41$ & $42-49$ & $45-52$ \\
Relief angle $\gamma$ (Japan) & $-4.50^{\circ}$ & $5.10^{\circ}$ & $25.10^{\circ}$ & $45.10^{\circ}$ \\
Relief angle $\gamma$ (Taiwan) & $-5.35^{\circ}$ & $4.67^{\circ}$ & $24.88^{\circ}$ & $44.67^{\circ}$ \\
\hline
\end{tabular}

Note: Depth of working is $23 \mathrm{~cm}$. 
Table 4. Measurement and calculated data of tiller blades

\begin{tabular}{|c|c|c|c|c|c|c|}
\hline \multirow[t]{2}{*}{ Blade type } & \multicolumn{6}{|c|}{ Tiller blade } \\
\hline & & A & & & $\mathrm{B}$ & \\
\hline \multicolumn{7}{|l|}{ Measurement data } \\
\hline Rotating speed of rotor (rpm) & & 181 & & & 262 & \\
\hline Rotary gears radio & & $21-24$ & & & $22-23$ & \\
\hline Forward speed of tractor $V(\mathrm{~cm} / \mathrm{sec})$ & & 37.2 & & & 52.8 & \\
\hline Tilling radius $R(\mathrm{~cm})$ & & 23 & & & 19.2 & \\
\hline Depth of working $H(\mathrm{~cm})$ & & 18 & & & 15.2 & \\
\hline Soil hardness $(\mathrm{cm})$ & & 14.8 & & & 14.8 & \\
\hline \multicolumn{7}{|l|}{ Calculated data } \\
\hline Tilling moving speed $v(\mathrm{~cm} / \mathrm{sec})$ & 235.5 & & 75.6 & 248.1 & 149.6 & 103.0 \\
\hline Tilling moving acceleration $a\left(\mathrm{~cm} / \mathrm{sec}^{2}\right)$ & 706.5 & & 75.6 & 248.1 & 149.6 & 103.0 \\
\hline Tilling times $t(\mathrm{sec})$ & 0.075 & & 0.187 & 0.05 & 0.07 & 0.08 \\
\hline Cutting angle $\beta$ & & $85.88^{\circ}$ & & & $84.28^{\circ}$ & \\
\hline Edge-curve angle $\alpha$ & & $59.70^{\circ}$ & & & $58.31^{\circ}$ & \\
\hline Blade scoop-angle $\beta_{1}$ & & $61.00^{\circ}$ & & $59.28^{\circ}$ & $69.28^{\circ}$ & $74.28^{\circ}$ \\
\hline Relief angle $\gamma$ & & $24.88^{\circ}$ & & $25^{\circ}$ & $16^{\circ}$ & $10^{\circ}$ \\
\hline
\end{tabular}

Note: Cultivation blade the back scoop-angle $\beta_{1}$ of A is $75.88^{\circ}$ and the relief angle $\gamma$ is $10^{\circ}$.

Table 5. Trajectory data in polar coordinates for tiller blades and cultivation blades

\begin{tabular}{|c|c|c|c|c|c|}
\hline & $\begin{array}{c}\text { Tiller blade } \\
\left(\gamma=25^{\circ}, a=3 v\right)\end{array}$ & & & $\begin{array}{l}\text { Cultivation blade } \\
\left(\gamma=10^{\circ}, a=v\right)\end{array}$ & \\
\hline & $r(\mathrm{~cm})$ & $\theta$ & & $r(\mathrm{~cm})$ & $\theta$ \\
\hline$P_{0}$ & 23.00 & $12^{\circ} 33^{\prime}$ & $\mathrm{P}_{0}^{\prime}$ & 23.00 & $12^{\circ} 33^{\prime}$ \\
\hline$P_{1}$ & 20.30 & $5^{\circ} 18^{\prime}$ & $\mathrm{P}_{1}^{\prime}$ & 20.78 & $-3^{\circ} 58^{\prime}$ \\
\hline$P_{2}$ & 17.70 & $-1^{\circ} 29^{\prime}$ & $\mathrm{P}_{2}^{\prime}$ & 18.57 & $-20^{\circ} 09^{\prime}$ \\
\hline$P_{3}$ & 15.11 & $-7^{\circ} 31^{\prime}$ & $\mathrm{P}_{3}^{\prime}$ & 16.32 & $-35^{\circ} 49^{\prime}$ \\
\hline$P_{4}$ & 12.56 & $-12^{\circ} 19^{\prime}$ & $\mathrm{P}_{4}^{\prime}$ & 14.09 & $-50^{\circ} 46^{\prime}$ \\
\hline$P_{5}$ & 10.24 & $-15^{\circ} 30^{\prime}$ & $\mathrm{P}_{5}^{\prime}$ & 11.91 & $-64^{\circ} 37^{\prime}$ \\
\hline$P_{6}$ & 7.86 & $-14^{\circ} 10^{\prime}$ & $\mathrm{P}_{6}^{\prime}$ & 9.74 & $-76^{\circ} 27^{\prime}$ \\
\hline$P_{7}$ & 6.01 & $-6^{\circ} 18^{\prime}$ & $\mathrm{P}_{7}^{\prime}$ & 7.74 & $-84^{\circ} 49^{\prime}$ \\
\hline$P_{8}$ & 5.03 & $12^{\circ} 11^{\prime}$ & $\mathrm{P}_{8}^{\prime}$ & 6.05 & $-87^{\circ} 21^{\prime}$ \\
\hline$P_{01}$ & 22.45 & $11^{\circ} 05^{\prime}$ & $\mathrm{P}_{01}^{\prime}$ & 22.54 & $9^{\circ} 14^{\prime}$ \\
\hline$P_{02}$ & 21.92 & $9^{\circ} 37^{\prime}$ & $\mathrm{P}_{02}$ & 22.10 & $5^{\circ} 56^{\prime}$ \\
\hline$P_{03}$ & 21.38 & $8^{\circ} 09^{\prime}$ & $\mathrm{P}_{03}$ & 21.66 & $2^{\circ} 37^{\prime}$ \\
\hline$P_{04}$ & 20.84 & $6^{\circ} 44^{\prime}$ & $\mathrm{P}_{04}^{\prime}$ & 21.22 & $0^{\circ} 4^{\prime}$ \\
\hline
\end{tabular}

3. The measurement temperature of the tiller blades using a infrared thermal imager with spray-welding technique

The area of automatic alloy powder welding on the surface of the tiller blades was $80 \times 120 \mathrm{~mm}$, some of the temperature measurement spots merely served as a reference (such as 1 4, and 14, 15 in Figure 7). Under the same film temperature orientation spot, the temperature of the thermal image obtained from welding by the heat imager was compared with that of the heat radiation of the surface after 8 seconds of welding. After data comparison, the errors for points $6,7,9$, and 10 are $2.50 \sim 2.60 \%$ and those for points $5,11,12$, and 13 are $1.93 \sim 2.48 \%$ (Table 6). All errors of the measurement points are within the measurement error of the imager, and the amount is $\pm 2 \%$. According to the analysis by the ANSYS system, point 8 is where the thickness and the reacting force of the material maximizes and therefore causes an error value of $2.48 \%$. Overall, the results of the temperature measurement reflect consistency with the data obtained from the field application. At the same time, when six pieces of tiller blades are being tested, the heat radiant temperatures obtained from the 
corresponding spots by the thermal imager were similar and distributed evenly. Therefore, the present data have proved that the coating surface of the tiller blades

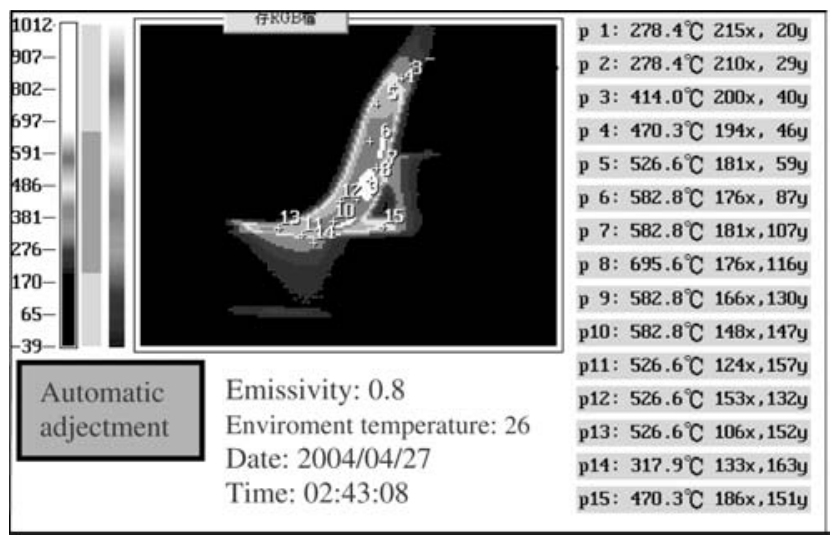

Fig. 7. The spots' temperature of the surface heat radian image obtained from thermal imager during the spray-welding process. treated with alloy powder welding would have more uniformity, precision and stability when using the alloy powder spray-welding mechanism developed in this study.

\section{The characteristics of abrasive wearing to nickel-based alloy}

There are two sets of specimens in this study; SUPHT, welded layer with heat treatment, and SUP-H, welded layer and they are spring steels (SUP-9) under the attrition of nickel-based alloy. Medium carbon steel and chrome steel balls were to rub the surfaces against the specimens and to conduct experiments on sliding attrition operator (SRV). Attrition results shown in Table 7 suggested that SUP-HT performs better than SUP-H in terms of the duration for attrition and the abrasive parameter. Meanwhile, the SUP-HT also has better anti-oxidizing function. The hardness parameter (HRc) on the coating is $58 \sim 60$. The adherence after

Table 6. Experimental data of instant heat image and heat radiation at the same measuring spots

\begin{tabular}{cccccc}
\hline $\begin{array}{c}\text { The spots } \\
\text { for } \\
\text { temperature } \\
\text { testing }\end{array}$ & Coordinates & $\begin{array}{c}\text { Instant temperature } \\
\text { shown with heat } \\
\text { image by } \\
\text { spray-welding } \\
(\mathrm{A})\left({ }^{\circ} \mathrm{C}\right)\end{array}$ & $\begin{array}{c}\text { Temperature shown } \\
\text { by radian heat } \\
\text { emitted from the } \\
\text { surface of the blades } \\
(\mathrm{B})\left({ }^{\circ} \mathrm{C}\right)\end{array}$ & $\begin{array}{c}\text { Difference } \\
(\mathrm{A}-\mathrm{B})\end{array}$ & $\begin{array}{c}\text { Error value } \\
(\%)\end{array}$ \\
\hline 5 & $\mathrm{X}=181, \mathrm{Y}=59$ & 936.5 & 526.6 & 409.9 & 2.48 \\
6 & $\mathrm{X}=176, \mathrm{Y}=87$ & 972.4 & 582.8 & 389.6 & 2.60 \\
7 & $\mathrm{X}=181, \mathrm{Y}=107$ & 972.4 & 582.8 & 389.6 & 2.60 \\
$8^{*}$ & $\mathrm{X}=176, \mathrm{Y}=116$ & 993.7 & 695.6 & 298.1 & 2.48 \\
9 & $\mathrm{X}=166, \mathrm{Y}=130$ & 972.8 & 582.8 & 389.6 & 2.50 \\
10 & $\mathrm{X}=148, \mathrm{Y}=147$ & 972.8 & 582.8 & 389.6 & 1.93 \\
11 & $\mathrm{X}=124, \mathrm{Y}=157$ & 934.3 & 526.6 & 407.7 & 1.93 \\
12 & $\mathrm{X}=153, \mathrm{Y}=132$ & 934.3 & 526.6 & 407.7 & 2.48 \\
13 & $\mathrm{X}=106, \mathrm{Y}=152$ & 936.5 & 526.6 & 409.9 & \\
\hline
\end{tabular}

Note: *Represents the maximum stress concentration location where the thickness is three times thicker than elsewhere.

Table 7. Results under the processing of line and point contact (by SRV) (Load: 100N, sliding stroke: 1.0 mm, frequency: 50Hz, test time: 24 min)

\begin{tabular}{lcccc}
\hline Parameter & \multicolumn{2}{c}{ Average friction coefficient } & \multicolumn{2}{c}{ Average depth of wear track $(\mu \mathrm{m})$} \\
\cline { 2 - 5 } Coating code & $\begin{array}{c}\text { S45C } \\
\text { line contact }\end{array}$ & $\begin{array}{c}\text { Chrome steel ball } \\
\text { point contact }\end{array}$ & $\begin{array}{c}\text { S45C } \\
\text { line contact }\end{array}$ & $\begin{array}{c}\text { Chrome steel ball } \\
\text { point contact }\end{array}$ \\
\hline SUP-H-2 & 0.7274 & 0.7246 & 28.67 & 88.67 \\
SUP-H-2.5 & 0.6365 & 0.6892 & 25.67 & 78.13 \\
SUP-H-3 & 0.6079 & 0.6444 & 22.49 & 74.47 \\
SUP-HT-2 & 0.6706 & 0.6984 & 25.44 & 64.67 \\
SUP-HT-2.5 & 0.6234 & 0.6765 & 23.33 & 61.06 \\
SUP-HT-3 & 0.5854 & 0.6366 & 21.18 & 58.19 \\
\hline
\end{tabular}

Note: *These numbers stand for film-thickness $(\mathrm{mm})$ of coating on spring steel specimens. 
compression has an A-class grading under a Scanning Electron Microscope (SEM). There is no significant difference between the overall parameters for these two specimens used here as a reference. A field-trial was conducted by using the developed automatic machine of spray-welding mechanism to carry out the nickel-based alloy welding. It is expected that this theory is applicable and the cost of production can be reduced.

\section{Field-trial experiment to determine the duration of attrition on the surface of the blades}

The results are shown in Table 8, and in Figures 8 and 9. When the tractor had plowed 20 ha, there was no significant change in the attrition of the surface of the blades with SUP-HT treatment. After 30 ha of plowing, the variation of the curve had a significant difference and became almost the same as that of the untreated

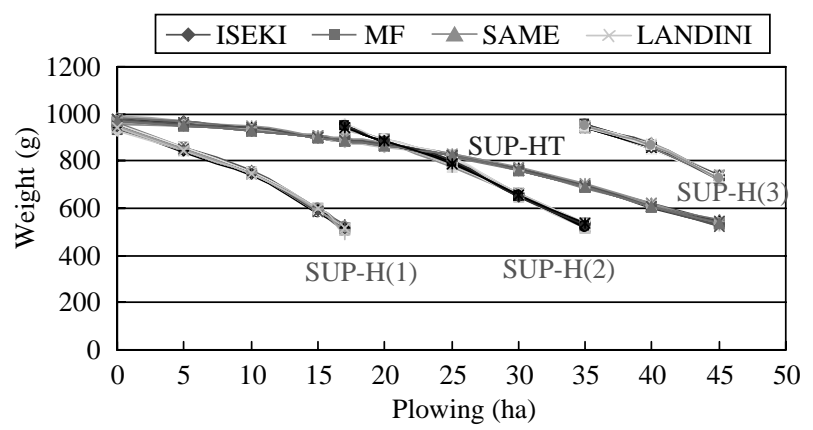

Fig. 8. Comparison of wearing results between SUP-HF and SUP-H specimens, (Yunlin area: sandy-loam soil). ones (SUP-H). Figures 8 and 9 illustrate the resulting curves of data collected from sample tractors of four different brands installed with two sets of tiller blades SUP-HT and SUP-H operating in both sandy-loam soil and gravel soil. The field trail results have shown that the SUP-HT blades performed excellently to both the sandy-loam soil area of 45 ha and gravel soil area of 65 ha based on the same replacement of 168 tiller blades (42 pieces are SUP-HT and 126 pieces are SUP-H). The SUP-HT is 2.6 times higher than SUP-H with respect to both types of soil, thus, the iron residue remained in the soil is $24 \mathrm{~kg}$ less for both soil types. The efficiency of the SUP-HT blades is found to be environment friendly.

\section{CONCLUSIONS}

This study validates and analyzes the mathematical models of the plowing dynamical exerted by the

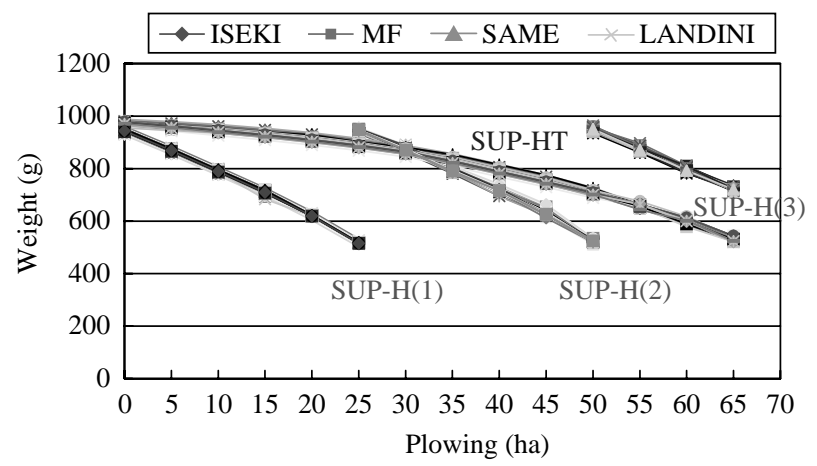

Fig. 9. Comparison of wearing results between SUP-HT and SUP-H specimens, (Chiayi, Tainan area: gravel soil).

Table 8. Results from field experiments

\begin{tabular}{lcccc}
\hline \multicolumn{1}{c}{ Coating code } & $\begin{array}{c}\text { SUP-HT (I) } \\
\text { (ha) }\end{array}$ & $\begin{array}{c}\text { SUP-H (1) } \\
\text { (ha) }\end{array}$ & $\begin{array}{c}\text { SUP-H (2) } \\
\text { (ha) }\end{array}$ & $\begin{array}{c}\text { SUP-H (3) } \\
\text { (ha) }\end{array}$ \\
\hline Sandy-loam soil & 45 & $0 \sim 17.3$ & $17.3 \sim 35$ & $35 \sim 45$ \\
Total weight A (g) & 40,656 & 39,196 & 39,281 & 39,159 \\
$\quad$ Abrasion total weight B (g) & 22,890 & 22,218 & 22,098 & 31,394 \\
Iron contain A-B (g) & 17,766 & 16,978 & 17,183 & 7,765 \\
$\quad$ Iron contain of piece (g) & 423 & 404 & 409 & \\
Iron residues amount (g) & & & & \\
(1)+(2)+(3)- (I) & 65 & $0 \sim 25$ & 24,160 & \\
Stone-gravel soil & 40,549 & 39,242 & 39,137 & 39,328 \\
Total weight A (g) & 22,988 & 22,502 & 22,289 & 30,998 \\
Abrasion total weight B (g) & 17,561 & 16,740 & 16,848 & 8,330 \\
Iron contain A-B (g) & 418 & 398 & & \\
Iron contain of piece (g) & & & & \\
Iron residues amount (g) & & & & \\
(1)+(2)+(3)- (I) & & & & \\
\hline
\end{tabular}

Note: (1), (2), and (3) represent the $1^{\text {st }}, 2^{\text {nd }}$ and $3^{\text {rd }}$ experiment data of tiller blades without surface hardening treatment. 
rotary blades. The trajectory curves designed correlate with the standard for tiller blades in Taiwan. A nickelbased alloy powder spray-welding technique was applied. An infrared thermal imager was used to collect and analyze the surface layer temperatures. Lab-based and field-based experiments on the duration of attrition were conducted. The following conclusions are drawn from the present studies.

1. The blade must be protected from intertwisting to ensure high efficiency and uniform resistance of the plow to soil. Theoretical and calculated cutting angles are found to be $85.88^{\circ}$ and $84.28^{\circ}$, respectively, while the theoretical and calculated edge-curve angles are $59.70^{\circ}$ and $58.31^{\circ}$.

2. At the measurement spots, both the instant heat image displayed in the thermal imager and the surface temperature of the heat radiation collected after eight seconds were consistent with earlier results. When these six pieces of tiller blades were tested at the same time, the six sets of heat radiant temperatures of the corresponding points obtained from the thermal imager were found similar and evenly distributed.

3. In the SRV testing mechanism experiment, the duration of attrition for the coating and the abrasive parameter has shown that SUP-HT specimens performed better than the SUP-H specimens. The SUP$\mathrm{HT}$ also has a better anti-oxidizing function with a hardness parameter $(\mathrm{HRc})$ of $58 \sim 60$. The adherence after compression has grading as A-class under Scanning Electronic Microscopy (SEM).

4. The field-trail experimental results showed that the SUP-HT blades performed excellently for both the sandy-loam with area of 45 ha and gravel soil with area of 65 ha based on the same replacement of 168 tiller blades (42 pieces are SUP-HT and 126 pieces are SUP-H). The plowing capacity of SUP-HT is 2.6 times higher than that of SUP-H with respect to both types of soil, thus, the iron residue remained in the soil is $24 \mathrm{~kg}$ less for both the soil types. To the environmental protection, the efficiency of the SUPHT blade should be recognized as well.

5. It can be proved that the coating surface of the tiller blades treated with alloy powder welding would increase uniformity, precision and stability when using the alloy powder spray-welding mechanism developed in this study. As it is applied to the real situation, the natural soil can free from the contamination of iron particle coming off the blades up to $618,000 \mathrm{~kg}$. Meanwhile, a labor cost of $7.5 \mathrm{hr}$ and equipment cost 4,620 NT can be saved per set of tractor, minimizing the cost of production. This is the first study of tractor that has considered environment pollution and production cost.

\section{REFERENCES}

1. Agriculture and Food Agency, Agriculture Statistics Yearbook, COA, Executive Yuan, Taipei, R.O.C. (2004).

2. Barker, D., "Electroless Depositing of Metals," Transactions of the Institute of Metal Finishing, Vol. 71, pp. 121-129 (1993).

3. Chen, L.H., "Analysis of Mechanism Design for Motion Performance of the Swing Nozzle Linkage-Rank Center Located on the Motion Line of Slider," Journal of Agricultural Machinery, Vol. 14, No. 1, pp. 1-8 (2005).

4. Ju, J.S., "Evaluation of the Usability of the Welding Nickel-Base Alloy on the Tiller Blade," Journal of National Chiayi Institute of Agriculture, Vol. 51, pp. 6782 (1997).

5. Ju, J.S. and Du, F.A., "The Manufactural of Agricultural Cutting Tools," R.O.C. Invention Patent No. I237547 (2005).

6. Ju, J.S. and Du, F.A., "An Automatic Thermal Sprayer for Cutting Tools," R.O.C. Utility Model Patent No. M25094 (2005).

7. Ju, J.S. and Du, F.A., "The Improved Structure of Agricultural Cutting Tools," R.O.C. Utility Model Patent No. M25894 (2005).

8. Ju, J.S. and Luan, J.M., "A Study of the Tiller Blade Plowing Forces and Its Surface Hardening after Powder Welding Treatment," Proceedings of the International Symposium on Automation and Mechanics of Agricultural and Bioproduction Systems, Chinese Institute of Agricultural Machinery, Taiwan, pp. 629-636 (2002).

9. Ju, J.S., Chang, C.W., and Luan, J.M., "Application of Infrared Thermal Imager in Determination of Coating Temperature Using Spray-Welding mechanism for Tiller Blades," Journal of Agricultural Machinery, Vol. 12, No. 4, pp. 77-92 (2003).

10. Ju, J.S., Hong, S.L., and Luan, J.M., "Development of Spray-Welding Coating Mechanism for Tiller Blades," Journal of National Chiayi University, Vol. 76, pp. 107137 (2005).

11. Ju, J.S., Luan, J.M., and Chang, C.W., "Trajectory Angles and Cultivating Dynamics for Tiller Blades," Journal of Agricultural Machinery, Vol. 13, No. 1, pp. 1-16 (2004).

12. Ju, J.S., Chao, C.Y., Luan, J.M., and Chang, C.W., "A Study on the Friction and Wear Abrasive of NickelBased Alloy Coatings for Tiller Blades," Journal of Agricultural Machinery, Vol. 13, No. 3, pp. 1-14 (2004).

13. Michael, D.F., "Composite Electroless Nickel Coatings for the Aerospace \& Airline Industries," Plating and Surface Finish, Vol. 85, pp. 248-252 (1997).

14. Parker, K., "Electroless Nickel: State of the Art," Plating and Surface Finish, Vol. 79, No. 3, pp. 29-33 (1992).

15. Sakai, J., A Theoretical Approach to the Mechanism and Performance of the Hand Tractor with a Rotary Tiller Together with Practical Application, JSAM Kyushu, 
Japan (1962).

16. Sakai, J., "Some Design Know-Hows of Edge-Curve Angle of Rotary Blades for Paddy Rice Cultivation," AMA, Vol. 8, No. 2, pp. 49-57 (1977).

17. Sakai, J., "Designing Process and Theories of Rotary Blades for Better Rotary Tiller (Part 1)," JARQ, Vol. 12, No. 2, pp. 86-93 (1978).

18. Sakai, J. and Shibata, Y., "Studies of the Design Engineering of Rotary Plates for the Rotary Tilling of Tractors, I-III," Bulletin of Faculty of Agriculture, Mei University, Vol. 49, pp. 163-181, Vol. 50, pp. 211-223, Vol. 51, pp. 145-155 (1975-6).

19. Sakai, J. and Shibata, Y., "Design Theories of ScoopSurface of Rotary Blades for Tractors," JSAM, Vol. 39, No. 1, pp. 11-20 (1977).

20. Sakai, J., Shibata, Y., and Taguchi, T., "Design Theory of Edge-Curves for Rotary Blade of Tractors," JSAM, Vol. 38, No. 2, pp. 183-190 (1976).

21. Taiwan Agricultural Mechanization Research and De- velopment Center, Directory of Taiwan Agricultural Machinery, Vol. 5, No. 6, pp. 10-11 (1996).

22. Xinmin, H. and Zongang, D., "The Wear Characteristics of Ni-P-SiC Composite Coating," Transactions of the Institute of Metal Finishing, Vol. 70, pp. $84-89$ (1992).

23. Yamada, T., Gotou, S., and Yamazaki, M., "Abrasive Wears of Tillage Blade (II)-Effects of Soil Properties on Abrasion and Cause and Effect Diagram," Journal of Agricultural Engineering Research, Vol. 53, No. 1, pp. 97-102 (1991).

24. Zhang, Y.Z., Wu, Y.Y., Sun, K.N., and Yao, M., "Characterization of Electroless Ni-P-PTFE Composite Deposits," Journal of Material Science Letters, Vol. 17, pp. 119-124 (1998).

25. Zheng, G., Ota, Y., Hiroma, T., and Kataoka, T., "Wear Resistance of Cultivator Tine (Part 1)," Journal of Agricultural Engineering Research, Vol. 58, No. 3, pp. 49-58 (1996). 